\title{
Determination and localization of oil components in living benthic organisms by fluorescence microscopy
}

\author{
E. Zeeck \\ Universität Oldenburg, Projekt Umweltentwicklung und -planung im küstennahen \\ Gebiet; D-2900 Oldenburg, Federal Republic of Germany
}

\begin{abstract}
Microspectrofluorometric measurements are made to determine uptake and distribution of oil in marine organisms after exposure to crude oil. Equipment combining fluorescence microscopy with spectral analysis of the fluorescence emission is described. After contamination with oil, the intestine content of Lumbricillus lineatus, Nereis diversicolor and Anaitides mucosa shows a fluorescence emission at long wavelengths with a maximum at about $550 \mathrm{~nm}$; this is in contrast to the fluorescence emission of these organisms without oil contamination. There is evidence that aromatic hydrocarbons are metabolized in the intestine of the worms-studied.
\end{abstract}

\section{INTRODUCTION}

Fluorescence spectroscopy is known as a very sensitive tool for the determination of many substances. When restricted to investigations within the visible or the near UV region of the spectrum, most aromatic hydrocarbons show fluorescence emission of high intensity. These substances are components of crude oil. Fluorescence spectroscopy therefore has been proposed for identifying traces of oil in sea water (e.g. Gordon \& Keizer, 1974).

At least as interesting as the proof of oil in sea water is the identification of oil in the tissue of organisms. Some advantages and results as well as difficulties in the use of fluorescence spectroscopy for the determination of oil in the tissue of benthic organisms will be outlined here.

\section{METHOD}

Since there are powerful analytical methods (e.g. gas chromatography in conjunction with mass spectrometry) for the analysis of samples containing traces of hydrocarbons and their metabolites, the question arises whether there is a need for such a method as fluorescence spectroscopy which gives much less detailed information with respect to the identification of single chemical compounds within complex mixtures.

Optical spectroscopy combined with microscopy offers the following a d vant a ge $s$ to the biologist (see also Kohen et al., 1978): (a) It enables the biologist to inspect small organisms. It is impossible for gas chromatography to analyze single organisms from meiofauna or microfauna. Using fluorescence microscopy it is possible to determine the distribution of several toxic substances in different body parts of these organisms. 
The smallest area for measurement with the equipment used in the investigations presented here has a diameter of only $0.5 \mu \mathrm{m}$. (b) It is possible to analyze the contamination of living organisms with this method. After death the distribution of toxic substances within the organism may change.

The main restriction s of the method are: (a) The combination of fluorescence spectroscopy and microscopy is restricted to the determination of substances which give fluorescence emission in the visible or near UV region of the spectrum. Therefore only a rather limited - nevertheless important - group of components, e.g. of crude oil, can be detected. (b) Tissue itself shows fluorescence. The shorter the wavelength of the excitation light, the more the tissue itself emits fluorescence light. It is difficult to decide between emission of tissue substances and oil components at wavelengths shorter than $450 \mathrm{~nm}$ (Hodgins et al., 1977).

Even at longer wavelengths it is in most cases necessary to perform spectral analysis of the emitted light to distinguish between fluorescence of oil and the tissue itself. Sometimes direct inspection of the fluorescence picture may be used to determine which part of the tissue contains oil and which part does not, but there are many situations where this is not possible without spectral analysis. In the following suitable equipment is described.

\section{EQUIPMENT}

Figure 1 gives a schematic representation of the fluorescence spectrometer unit. A Zeiss fluorescence microscope with Neofluar optics is fitted with filter combinations for the epifluorescence method, e.g. the filter combination $\mathrm{H} 365$ with fluorescence excitation at $365 \mathrm{~nm}$ and observation of fluorescence emission at wavelengths longer than $397 \mathrm{~nm}$. The light source is a stabilized high pressure mercury (or xenon) lamp. A photometer 03 serves for selecting the measurement area by a suitable diaphragm. It is followed by a zoom lens (Zeiss No. 474340 and 477 156) for optical fitting of the monochromator and the photomultiplier, the monochromator (Jobin Yvon grating monochromator $\mathrm{H} 10$ ) and the photomultiplier. The latter should show only little dependence of sensitivity on wavelength in the region studied, as e.g. the type RCA C 31 034; it is followed by a preamplifier (Ortec 9301) and an amplifier (an Ortec Brookdeal photon counter 501/5014 is used here but for most purposes it is not necessary to use photon counting techniques). A strip chart recorder may be the end of the chain.

As the spectrum obtained by this combination of instruments is a superposition of the fluorescence spectrum on the one hand and the spectrum of the optics of the instrument and of the photomultiplier on the other, it is helpful to use a computer for unfolding these components. To do this, the data are transferred by a microprocessor and a tape recorder to a magnetic tape.

\section{RESULTS AND DISCUSSION}

Initial results were obtained by studying selected organisms of the tidal flat of the German North Sea coast: Anaitides mucosa, Nereis diversicolor and Lumbricillus lineatus. These worms were exposed for five days to oil-in-water dispersions $(0.5 \%$ Arabian light oil in sea water). Experiments with exposure to different concentrations of the water-soluble fraction of crude oil are being continued and will be reported elsewhere. 


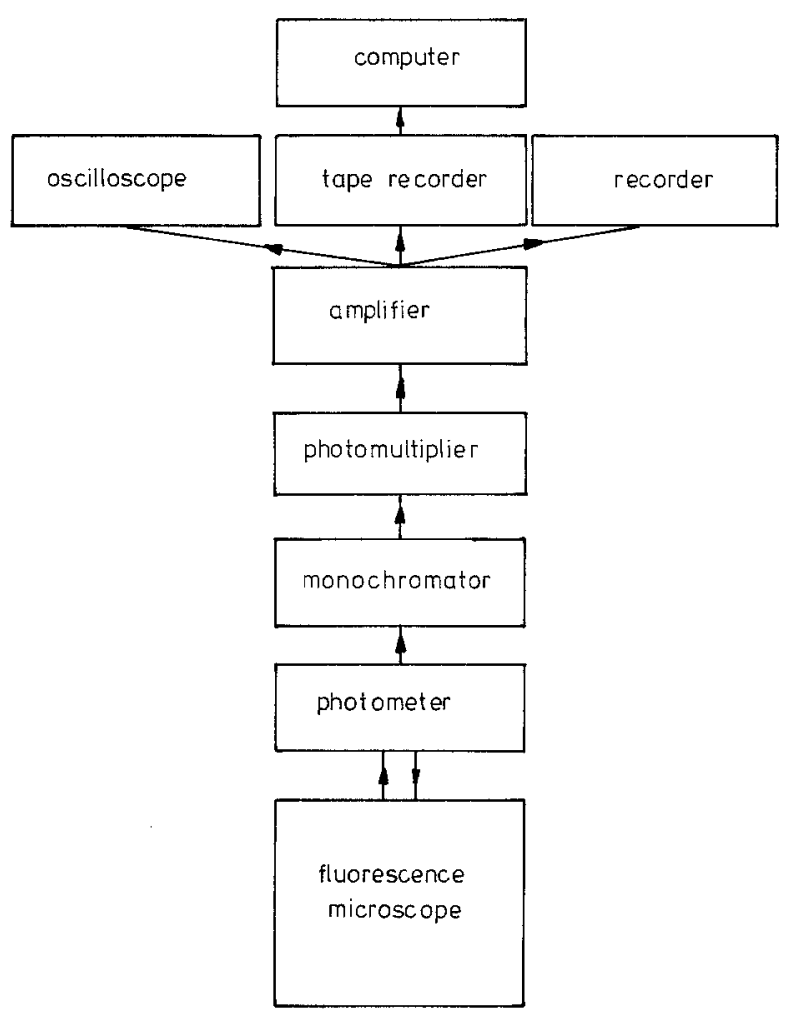

Fig. 1. Schematic description of the fluorescence spectrometer

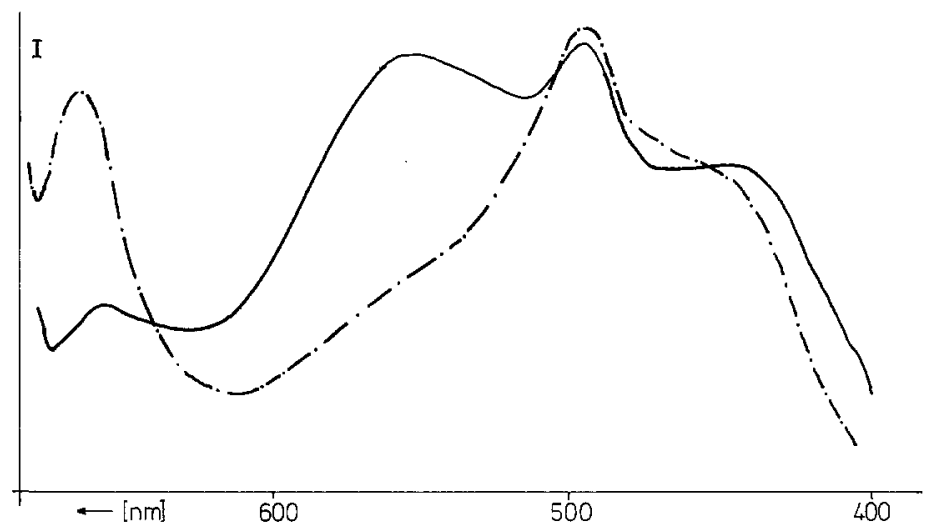

Fig. 2. Fluorescence spectra of the intestine content of Anaitides mucosa; solid line: contamination with petrol, broken line: uncontaminated 
Figure 2 shows spectra of the intestine content of Anaitides mucosa with and without exposure to oil. Spectra of analogous regions of Nereis diversicolor and Lumbricillus lineatus are similar.

The spectra in Figure 2 are superpositions of the fluorescence spectra and of the spectrum of the instrument, as mentioned above. The maximum at $490 \mathrm{~nm}$ is given by a high translucence of the microscope optics together with a maximum of sensitivity of the photomultiplier.

The most interesting differences between the spectra are located in the region between 500 and $600 \mathrm{~nm}$. The maximum at about $550 \mathrm{~nm}$ only in the spectrum of the oilexposed organisms indicates accumulation or generation of substances with long wavelength fluorescence in the intestine. The fluorescence spectrum of crude oil itself shows a maximum at a much shorter wavelength.

Differences in the spectra in the region above $650 \mathrm{~nm}$ are of no interest in this context. They are caused by different contents of chlorophyll or chlorophyll metabolites in the intestine from the food of the worms (diatoms) and show no reproducible dependence on oil contamination.

Using gas chromatographic analysis, van Bernem (personal communication) found that after exposure to oil larger organisms (Arenicola marina) accumulated perylene, benzo-b-fluoranthene, benzo-c-phenanthrene, benzo-b,c-fluorene, pyrene, fluoranthene and phenanthrenes in addition to benzo-a-pyrene, benzo-e-pyrene, methylchrysene and chrysene; the latter substances were also found (at much lower concentrations) in the uncontaminated organisms. Many other authors, too, report organismic uptake of polynuclear aromatic hydrocarbons from petrol (e.g. Anderson, 1977; Varanasi \& Malins, 1977).

But the maximum of fluorescence emission at about $550 \mathrm{~nm}$ cannot be explained by accumulation of aromatic hydrocarbons. There must be polar substances, too, probably by metabolizing the aromatic hydrocarbons. This metabolic process seems to occur within the intestine of these organisms. The intestine content of Lumbricillus lineatus showed drops of different colour under the fluorescence microscope (excitation at $365 \mathrm{~nm}$ ), the colour ranging from blue over light and dark yellow to brown. Spectroscopically the emission of these drops differed by the relative height of the maximum at $550 \mathrm{~nm}$, the brownish drops showing the highest relative intensity at this point, indicating the highest content of metabolized compounds.

The assumption that this maximum at $550 \mathrm{~nm}$ is caused by metabolized compounds of crude oil is based on the following facts: Crude oil itself shows relatively low intensity of fluorescence emission at wavelengths longer than $500 \mathrm{~nm}$ (fluorescence excitation at $365 \mathrm{~nm}$ ). A fluorescence emission at long wavelengths is due to compounds with large pi-electron systems as polycyclic aromatic hydrocarbons. Examples for fluorescence emission of these hydrocarbons are: chrysene $387 \mathrm{~nm}$, pyrene $397 \mathrm{~nm}$, phenanthrene $367 \mathrm{~nm}$, benzo-a-pyrene $405 \mathrm{~nm}$, perylene $465 \mathrm{~nm}$, fluoranthene $477 \mathrm{~nm}$, tetracene $511 \mathrm{~nm}$ (average wavelength of the fluorescence spectrum, according to Berlman, 1971).

Obviously, it is not possible to construct a maximum of fluorescence emission at $550 \mathrm{~nm}$ with these substances. But the introduction of the amino or hydroxyl group causes bathochromic shifts in the spectra of the aromatic hydrocarbons which can be enlarged by additional groups bound to the same ring system as for example the carbonyl group. 
As examples for these effects data may be given for benzene and some benzene derivatives (Berlman, 1971): benzene $282 \mathrm{~nm}$, phenol (in methanol) $300 \mathrm{~nm}, 1,4$-dimethoxy-benzene $324 \mathrm{~nm}, 2,3$-dihydroxy benzoic acid $431 \mathrm{~nm}$, aniline (in ethanol) $341 \mathrm{~nm}$, 1,3-diaminobenzene $439 \mathrm{~nm}$.

For polycyclic aromatic hydrocarbons, the situation is of course more complicated but the tendency is the same. Thus the wavelength of the fluorescence emission of fluoranthene $(477 \mathrm{~nm})$ is shifted by the introduction of an amino group to $552 \mathrm{~nm}$ (3amino fluoranthene in ethanol). There will be no difficulty constructing a maximum of fluorescence emission at about $550 \mathrm{~nm}$ by a combination of hydrocarbon derivatives containing hydroxy or amino or other polar groups. At present, there are not enough spectral data available to produce a complete catalogue of all compounds which could contribute to such fluorescence emission, and moreover additional data from other analytical methods should be used to select the really important compounds.

However, it is possible to state that not the hydrocarbons themselves but their derivatives with polar substituents give rise to the fluorescence emission at $550 \mathrm{~nm}$ which was observed in the intestine of oil-contaminated organisms.

In principle it is possible that substances with these spectral properties which are present in crude oil in small concentrations are accumulated by the organisms, but it is not clear by what mechanism this accumulation occurs in the intestine. The fact that the polar derivatives are more soluble in water than the pure hydrocarbons can be excluded for such an accumulation process, as the fluorescence was not emitted by a homogeneous content of the intestine of Lumbricillus lineatus but by single drops, different drops showing different relative intensities of the fluorescence maximum at $550 \mathrm{~nm}$, as mentioned above.

On the other hand it is well known that metabolism of polycyclic aromatic hydrocarbons in organisms leads to derivatives of the type discussed here. Hydroxyl groups are introduced into the hydrocarbons via the formation of epoxy derivatives (Sims \& Grover, 1974; Malins, 1977; Jerina et al., 1979; Schäfer-Ridder, 1979). This was not only observed in mammalian tissue but also in invertebrates (Varanasi \& Malins, 1977; Anderson, 1978; Ernst, 1979). Anderson reported the metabolism of benzo-a-pyrene by aryl hydrocarbon hydroxylases in Spodoptera, in Mytilus edulis and in Geukensia demissa; Ernst studied the metabolic transformation of $1-\left(1-{ }^{14} \mathrm{C}\right)$ naphthol in Mytilus edulis and found metabolites of high polarity. Whereas mammals initiate the oxidation of aromatic hydrocarbons by the incorporation of one atom of molecular oxygen to form arene oxides and further metabolize these oxides to trans-dihydrodiols, bacteria incorporate both atoms of molecular oxygen and cis-dihydrodiols are formed. Further oxidation leads to the formation of catechols (Gibson, 1976).

It therefore seems likely that the fluorescence emission observed in the intestine of the oil-contaminated species mentioned above is due to substances formed by metabolism of oil components. Still open is the question whether this metabolism is caused by enzymes of the worms themselves or by oil-degrading bacteria. These bacteria will be present in the oil-in-water dispersions and may have entered the intestine of the worms together with oil drops. Investigations are continuing in this field.

Acknowledgements. Some of the studies described in this manuscript were carried out in collaboration with C. Matuschek. I am indebted to M. Gewers and J. Krollpfeiffer for technical assistance, to 
Dr. L. Trapp, Carl Zeiss Comp., for technical information and to Dr. O. Giere for making available to me the species Lumbricillus lineatus after exposure to crude oil. The studies were supported by the Umweltbundesamt, Berlin.

\section{LITERATURE CITED}

Anderson, J. W., 1977. Responses to sublethal levels of petroleum hydrocarbons: Are they sensitive indicators and do they correlate with tissue contamination? In: Fate and effects of petroleum hydrocarbons in marine organisms and ecosystems. Ed. by D. A. Wolfe. Pergamon Press, Oxford, 95-114.

Anderson, R. S., 1978. Developing an invertebrate model for chemical carcinogenesis: Metabolic activation of carcinogenesis. - Comp. Pathobiol. 4, 11-24.

Berlman, I. B., 1971. Handbook of fluorescence spectra of aromatic molecules. Acad. Press, New York, $379 \mathrm{pp}$.

Ernst, W., 1979. Metabolic transformation of $1-\left(1-{ }^{14} \mathrm{C}\right)$ naphthol in bioconcentration studies with the common mussel Mytilus edulis. - Veröff. Inst. Meeresforsch. Bremerhaven 17, 233-240.

Gibson, D. T., 1976. Initial reactions in the bacterial degradation of aromatic hydrocarbons. - Zbl. Bakt., ParasitKde. (Abt. 1., Reihe B) 162, 157-168.

Gordon, D. C. \& Keizer, P. D., 1974. Estimation of petroleum hydrocarbons in sea water by fluorescence spectroscopy: Improved sampling and analytical methods. - Tech. Rep. Fish. Res. Bd Can. 481, 1-29.

Hodgins, H. O., Gronlund, W. D., Mighell, J. L., Hawkes, J. W. \& Robish, P. A., 1977. Effect of crude oil on trout reproduction. In: Fate and effects of petroleum hydrocarbons in marine organisms and ecosystems. Ed. by D. A. Wolfe. Pergamon Press, Oxford, 143-150.

Jerina, D. M., Yagi, H., Thakker, D. R., Karle, J. M., Mah, H. D., Boyd, D. R., Gadaginamath, G., Wood, A. W., Buening, M. et al., 1979. Stereoselective metabolic activation of polycyclic aromatic hydrocarbons. In: Pharmacology: international congress proceedings. Ed. by Y. Cohen. Pergamon Press, Oxford, 7 (11), 53-62.

Kohen, E., Kohen, C., Hirschberg, J. G., Wouters, A. \& Thorell, B., 1978. Multisite topographic microspectrofluorometry of intercellular and exogeneous fluorochromes. - Photochem. Photobiol. 27, 259.

Malins, D. C., 1977. Metabolism of aromatic hydrocarbons in marine organisms. - Ann. N. Y. Acad. Sci. $298,482-486$.

Schäfer-Ridder, M., 1979. Carcinogenese durch polycyclische aromatische Kohlenwasserstoffe. Nachr. Chem. Tech. 27, 4-6.

Sims, P. \& Grover, P. I., 1974. Epoxides in polycyclic aromatic hydrocarbon metabolism and carcinogenesis. - Adv. Cancer Res. 20, 165-172.

Varanasi, U. \& Malins, D. C., 1977. Metabolism of petroleum hydrocarbons: Accumulation and biotransformation in marine organisms. In: Effects of petroleum on arctic and subarctic marine environments and organisms. Ed. by D. C. Malins. Acad. Press, New York 1, 1-321. 